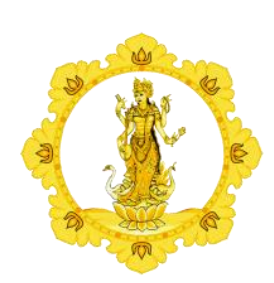

KALANGWAN

JURNAL PENDIDIKAN AGAMA, BAHASA DAN SASTRA

Vol. 11 No. 2 September 2021

\begin{tabular}{|l|l|l|}
\hline p-ISSN : 1979-634X & e-ISSN : 2686-0252 & http://ejournal.ihdn.ac.id/index.php/Kalangwan \\
\hline
\end{tabular}

\title{
KAJIAN PSIKOLOGI HUMANISTIK TOKOH UTAMA DALAM NOVEL DUA GARIS BIRU KARYA LUCIA PRIANDARINI
}

\author{
Oleh : \\ Iin Inayah ${ }^{1)}$, Cintya Nurika Irma ${ }^{2)}$ \\ ${ }^{12)}$ Universitas Peradaban \\ E-mail: inayahata99@gmail.com ${ }^{1)}$, Cintya_nurikairma@yahoo.co.id ${ }^{2)}$
}

Diterima 12 Juli 2021, direvisi 10 Agustus 2021, diterbitkan 31 September 2021

\begin{abstract}
Abstrak
Penelitian ini bertujuan untuk mendeskripsikan dan menjelaskan aspek-aspek psikologis berdasarkan kajian psikologi humanistik tokoh utama dalam novel Dua Garis Biru karya Lucia Priandarini. Penelitian ini merupakan jenis penelitian kualitatif dengan metode deskriptif. Teknik yang digunakan adalah teknik pengumpulan data, teknik triangulasi dan teknik analisis data merujuk pada analisis interaktif Miles dan Huberman. Analisis data dilakukan dengan menandai dan menentukan teks novel, mengklasifikasikan teks novel, dan menyimpulkan hasil klasifikasi teks novel yang selaras dengan kajian psikologi humanistik. Hasil penelitian menunjukkan bahwa tokoh utama mampu memenuhi aspek kebutuhan humanistik. Tujuh aspek kebutuhan humanistik antara lain kebutuhan fisiologis, kebutuhan akan rasa aman, kebutuhan sosial, kebutuhan akan dihargai, kebutuhan intelektual, kebutuhan estetis, dan kebutuhan mengaktualisasikan diri.
\end{abstract}

\section{Kata Kunci : Psikologi, Kajian Humanistik, Novel Dua Garis Biru}

\section{PENDAHULUAN}

Pikiran dan kejiwaan seseorang tak lepas dari kehidupan sehari-hari. Senantiasa semua orang akan berpikir dan merasakan jiwa pada rasa emosional, tindak tutur atau perilaku serta cara bersosialisasi dengan orang satu maupun orang lain. Berarti ada benarnya bila Endaswara (2013: 96) berpendapat bahwa psikologi sastra adalah kajian sastra yang memandang karya sebagai aktivitas kejiwaan. Dalam hal ini, karya sastra tidak terlepas dari psikologi seseorang. Sebagai pengarang novel, ia akan menggunakan sebagian imanijasinya dengan berpikir sesuai dengan rasa jiwa yang tinggi. Dengan pemikiran dan perasaan dalam menulis karya sastra. 
Pengarang menggunakan sebagian ceritanya bersifat fiktif belaka atau dalam keadaan peristiwa yang nyata ditulis oleh setiap pengarang dalam karya sastra.

Penelitian yang dilakukan oleh Rosidi dalam Marwah dan Aam (2020: 18) menyatakan bahwa psikologi humanistik mencakup pikiran, perasaan dan kemauan, sehingga aliran ini memperhatikan secara serius mengenai nilai-nilai kebebasan dan kualitas kemanusiaan. Adapun penjelasan dari teori lain yang dilakukan oleh Rachmahana (2008: 99) Psikologi humanistik atau disebut juga dengan nama psikologi kemanusiaan adalah suatu pendekatan yang multifaset terhadap pengalaman dan tingkah laku manusia, yang memusatkan perhatian pada keunikan dan aktualisasi diri manusia. Menurut Ekawati dan Nevi (2019: 266) menyatakan bahwa Teori humanistik bertujuan memanusiakan manusia seutuhnya yang kaffah sebagai makhluk ciptaan Allah SWT. Menurut Kasmi (2017:14) menyatakan bahwa humanisme merupakan pemahaman tentang kemanusiaan. Menurut Friedman dan Schustack dalam Nurwatie dkk menyatakan bahwa teori humanistik menggunakan pendekatan yang lebih spesifik daripada pendekatan lainnya karena berfokus pada kebutuhan-kebutuhan dasar dan aspek-aspek dalam kehidupan manusia. Dewi, dkk. (2018: 70) menyatakan bahwa teori psikologi humanistik adalah manusia yang didasari oleh kerangka-kerangka kebutuhan. Dari beberapa penjelasan teori psikologi humanistik di atas dapat disimpulkan bahwa psikologi humanistik adalah teori yang berlandaskan manusia yang saling membutuhkan orang lain untuk memenuhi kebutuhan dirinya baik pada aspek akal, perasaan, perilaku manusia, keinginan, rasa keamanan, perhatian, dan aktualisasi diri manusia.

Penelitian terhadap aspek psikologi sastra dalam sebuah karya sastra yang secara penuh sangat diperlukan guna mendapatkan pembedahan dalam novel yang dikaji sesuai dengan teori psikologi humanistik secara mendalam. Ada beberapa aspek-aspek psikologi humanistik dalam teori Maslow antara lain: (a) kebutuhan fisiologis (physiological needs); (b) kebutuhan akan rasa aman (safety), $\quad$ (c) kebutuhan sosial, (d) kebutuhan untuk dihargai (esteem needs); (e) kebutuhan intelektual (intellectual needs), (f) kebutuhan estetis (aesthetic needs), dan

(g) kebutuhan mengaktualisasikakan diri (sefl actialization) (Jarvis, 2006: 94-95).

Teori yang dikaji dalam psikologi humanistik Abraham Maslow adalah salah satu teori psikologi sebagai landasan untuk mengetahui aspek-aspek yang didalam sebuah novel. Novel merupakan sebuah karya sastra yang mengungkapkan emosional, imajinatif yang ditulis oleh pengarang sehingga dapat di baca dan nikmati oleh khalayak. Salah satu yang dikaji dalam novel tersebut adalah novel Dua Garis Biru karya Lucia Priandarini. Hal ini, terdapat aspekaspek psikologi humanistik dalam setiap tokoh pada cerita novel tersebut yang memiliki cara berpikir, emosional, imajinatif, watak dan perilaku yang berbeda.

Novel Dua Garis Biru karya Lucia Priandarini merujuk pada remaja muda yang sedang merasakan kisah asmara. Akan tetapi, dari kisah asmara merekaseperti nasi yang sudah menjadi bubur. Rasa malu, pendosa, jiwa dan pikiran merasa tidak ada artinya. Hal ini menjelaskan bahwa psikologi yang lebih banyak memikirkan kelemahan manusia daripada memikirkan kekuatan manusia. Psikologi tersebut meneliti kesalahan-kesalahan dan mengabaikan kebaikan. Pohan dalam penelitiannya di Kecamatan Na IX-X Kabupaten Labuhanbatu Utara ada beberapa faktor penyebab pernikahan dini yaitu pemaksaan dari orang tua, pergaulan bebas, rasa keingintahuan tentang dunia seks, faktor ekonomi, faktor lingkungan, dan rendahnya pendidikan.

Berdasarkan uraian latar belakang di atas, rumusan masalah dalam penelitian ini ialah bagaimana aspek-aspek psikologis berdasarkan kajian psikologi humanistik tokoh utama dalam novel Dua Garis Biru karya Lucia Priandarini? Adapun tujuan dalam penelitian ini yaitu untuk mendeskripsikan dan menjelaskan aspek-aspek psikologis berdasarkan kajian psikologi humanistik tokoh utama dalam novel Dua Garis Biru karya Lucia Priandarini. 


\section{METODE}

Penelitian ini menggunakan metode deskriptif. Data dalam penelitian ini berupa kata, frasa atau kalimat yang didalamnya menunjukkan aspek-aspek kebutuhan psikologi humanistik teori Abraham Maslow. Objek penelitian ini adalah novel Dua Garis Biru karya Lucia Priandarini yang diterbitkan oleh PT Gramedia Pustaka Utama, Jakarta, tahun 2019 dengan tebal buku sebanyak 208 halaman. Teknik pengumpulan data digunakan dengan teknik membaca dan teknik mencatat. Teknik triangulasi yang digunakan dalam penelitian ini adalah tiangulasi sumber, tiangulasi teori, dan triangulasi metode. Selanjutnya, teknik analisis data merujuk pada analisis interaktif Miles dan Huberman.

\section{PEMBAHASAN}

Novel Dua Garis Biru Karya Lucia Priandarinimerupakan kisah dua remaja yang mengalami kegagalan dalam hidup karena melakukan pergaulan bebas. Pernikahan dini adalah solusi utama untuk menyatukan mereka walaupun kedua belah pihak dari keluarga merasa tidak menerima keadaan tersebut. Namun,dengan keadaanlah yang memaksa mereka untuk melakukan pernikahan dini. Walaupun dari kedua pasangan kekasih tidak adanya unsur paksaan dalam melakukan hubungan.

Beberapa aspek kebutuhan humanistik dalam novel Dua Garis Biru karya Lucia Priandarini antara lain kebutuhan fisiologis, kebutuhan akan rasa aman, kebutuhan sosial, kebutuhan untuk dihargai, kebutuhan intelektual, kebutuhan estetis dan kebutuhan mengaktualisasikan diri.Kebutuhan Fisiologis, kebutuhan fisiologis merupakan kebutuhan akan fisik pada manusia berupa seks, tidur, makan, minum dan lain sebagainya.Kebutuhan akan rasa aman, kebutuhan akan rasa aman merupakan kebutuhan akan rasa aman berupa manusia yang menginginkan dilindungi dari lawan atau manusia yang melindunginya dari lawan, sehingga dari rasa aman tersebut timbulah rasa lain berupa kenyamanan. Kebutuhan sosial merupakan kebutuhan manusia yang dapat berinteraksi dan bersosial dengan satu orang atau kelompok sehingga memiliki tujuan yang sama.

Kebutuhan untuk dihargai, kebutuhan untuk dihargai merupakan kebutuhan manusia yang ingin dihargai, menginginkan dirinya untuk diapresiasikan oleh banyak orang. Biasanya dari kebutuhan tersebut manusia berupaya untuk menggali kemampuan atau kompetensi agar dirinya dapat dihargai.Kebutuhan Intelektual, kebutuhan intelektual merupakan kebutuhan manusia yang memiliki kemampuan atau kompetensi dengan daya pikir yang cerdas.

Kebutuhan estetis, kebutuhan estetismerupakan kebutuhan manusia yang menginginkan dari segi penampilan yang rapi, indah dipandang oleh orang lain. Sehingga dari itu, manusia akan merasakan puas dengan sanjungan orang lain. Kebutuhan mengaktualisasikan diri, kebutuhan mengaktualisasikan diri merupakan kebutuhan manusia yang sangat tinggi untuk tercapainya cita-cita, karier, mengembangkan bakat dan berambisi pada kompetensi yang akan dilakukan. Adapun aspek-aspek psikologi tokoh utama dalam novel Dua Garis Biru karya Lucia Priandarini akan dijelaskan lebih lanjut sebagai berikut:

\section{Kebutuhan Fisiologis (physioligical needs)}

Di dalam novel Dua Garis Biru karya Lucia Priandarini dijelaskan bahwa Dara dan Bima yang membutuhkan fisiologis seperti tersenyum, dan bertatapan. Dari kebutuhan itu dapat dirasakan oleh Dara dan Bima sehingga mereka merasakan kebahagiaan bersama. Berikut contoh penjelasan dalam novel Dua Garis Biru karya Lucia Priandarini yang menunjukkan hal tersebut.

"Keduanya bertatapan dan tersenyum malu-malu. "Saranghaeyo," ucap Dara lirih. Bima semakin mendekatkan diri pada Dara. Bibir Bima mendarat di bibir Dara. Tangan Bima mendekatkan punggung Dara ke sisinya. Dara melingkarkan kedua lengannya ke leher Bima. Dekat, erat, tak ingin lepas. Di luar, hujan turu rintik-rintik.” (DGB, 2019: 20-21). 
Dara yang membutuhkan fisiologis seperti tidur. Hal ini, akan membuat Dara menjadi lebih baik lagi dalam melakukan aktifitas. Dengan tidur, rasa lelah dan kepenatan menjadi baik. Akan tetapi, terdapat dampak buruk terhadap Dara usai tertidur. Dara teringat kembali tentang peristiwa kejadian siang yang membuat dirinya mengingat sesuatu. Dara menyesal melakukan hal yang tidak diinginkan bersama Bima kekasihnya. Berikut contoh penjelasan dalam novel Dua Garis Biru karya Lucia Priandarini yang menunjukkan hal tersebut.

"Dara ketiduran hingga langit sudah gelap. Saat terbangun, ia menatap tempat tidurnya yang berantakan sambil mengingat peristiwa tadi siang. Seprainya kusut, sama kusutnya dengan perasaannya yang kini belum ia kenali. ”(DGB, 2019: 23).

\section{Kebutuhan Akan Rasa Aman (Safety)}

Bima yang jangkung melindungi dan menjaga Dara dari terik panasnya matahari pada saat olahraga di lapangan. Sehingga dari rasa perhatian itu memberikan kenyamanan dan rasa aman terhadap Dara. Berikut contoh penjelasan dalam novel Dua Garis Biru karya Lucia Priandarini yang menunjukkan hal tersebut.

“... Bima yang jangkung mencoba melindunginya dari sinar matahari”. (DGB, 2019: 26).

Bima yang berjanji dan tidak akan meninggalkan Dara itu merupakan bukti kebutuhan akan rasa aman pada Dara. Dimana dari bukti yang diucapkan oleh Bima, Dara merasakan ketenangan dan rasa aman dengan apa yang dilakukan oleh Bima. Berikut contoh penjelasan dalam novel Dua Garis Biru karya Lucia Priandarini yang menunjukkan hal tersebut.

"Bima meraih tangan Dara. "Aku serius, Ra. Aku serius waktu aku bilang aku nggak akan ninggalin kamu lagi. (DGB, 2019: 72).

\section{Kebutuhan Sosial}

Bima yang biasanya bergabung dengan teman tongkrongannya dan menyapa tetangganya yang setiap Bima melewati jalan menuju rumahnya. Namun sejak kejadian itu, Bima hanya terdiam dan membisu untuk tidak ikut bergabung dengan teman sebayanya dan lak lagi menyapa tetangga rumahnya. Berikut contoh penjelasan dalam novel Dua Garis Biru karya Lucia Priandarini yang menunjukkan hal tersebut.

"Biasanya Bima akan turun dan menuntun sepeda motornya, menyapa ibu-ibu yang lewati sebelum mereka menyapa lebih dulu. Tapi kali ini Bima hanya menunduk sambil berlalu.

“... Biasanya Bima akan mampir bareng setengah jam, sekedar mengobrol dan dan memetik gitar. Tapi kini ia hanya menggeleng dan berlalu.” (DGB, 2019: 50-51).

Dara dan Bima biasanya bergaul dengan teman kelasnya, saling bercanda dikelas. Sejak mereka mempunyai rahasia besar dan permasalahan yang berat bagi mereka. Bima dan Dara sekarang jarang berinteraksi dengan temannya dikelas, jarang bercanda dan tertutup. Berikut contoh penjelasan dalam novel Dua Garis Biru karya Lucia Priandarini yang menunjukkan hal tersebut.

"Mereka berdua kenapa sih? Jadi jarang nongkrong," ada yang suara.

"Tahu deh. Pada Jarang bercanda juga," teman lain menimpali. Ada jeda.

"Dara nggak cerita ke lo, Vin?" salah seorang akhirya bertanya. Vini menggeleng pelan." (DGB, 2019: 80).

4. Kebutuhan untuk Dihargai (Esteem Needs) 
Dara yang tak ingin kalah dan selalu ingin dihargai oleh Bima serta kawan dekatnya, terpaksa Dara memakan kerang agar tidak terlihat lemah oleh Bima Pacarnya. Berikut contoh penjelasan dalam novel Dua Garis Biru karya Lucia Priandarini yang menunjukkan hal tersebut.

"Jangan mau dibilang lemah. Buktiin! Makan, Dar!" Vini mengompori, yang lain menimpali, “Makan! Makan! Makan!”. (DGB, 2019: 30)

Bima yang selalu ingin terlihat terkesan untuk dihargai dan dapat menyakinkan ayahnya, sekalipun ia paham betul bahwa nilai akademik tidak akan menjamin dirinya untuk kuliah dengan pilihannya. Ayah Bima yang menanyakan perihal lanjut kuliah dimana, dengan tegas Bima melontarkan kuliah di Jakarta agar terlihat sangat berani yang tanpak pada kutipan di bawah ini.

“... Jadi, habis lulus mau apa?” Bapaknya tidak bertanya habis lulus mau kuliah di mana, tapi mau ngapain.”

“... Kuliah di Jakarta”, jawab Bima singkat. Ingin kesan yakin, padahal tidak.” (DGB, 2019: 80-81).

\section{Kebutuhan Intelektual (Intellectual Needs)}

Ibu Bima yang telah mengetahui dan memaklumi kemampuan Bima dalam bidang akademik dengan kapasitas dan terbatas. Sehingga belajar sampai mati-matian pun akan nilai akademiknya sedikit. Berikut contoh penjelasan dalam novel Dua Garis Biru karya Lucia Priandarini yang menunjukkan hal tersebut.

“... Sudah biasa. Orang tuanya pun sudah maklum. mau bagaimana lagi? Belajar matimatian pun kapasitas dan kemampuan otaknya cuma sebatas itu.” (DGB, 2019: 52).

Selanjutnya, keadaan Dara yang sangat rumit karena memiliki rahasia yang sangat besar. Namun dengan kecerdasan yang Dara miliki. Ia mampu mengerjakan soal UTS dan semua kegiatan nilai akademiknya melalui kutipan di bawah ini.

“... Sekacau apa pun situasi, Bima yakin Dara pasri bisa mengerjakan UTS dan semua kegiatan akademisnya.” (DGB, 2019: 79).

\section{Kebutuhan Estetis (Aesthatic Needs)}

Dara anak yang cerdas dan cantik. Dengan memakai baju apapun ia sangat cantik. Dara merupakan kembang sekolah yang akan tidak khawatir untuk memilih warna ikat rambut yang akan ia kenakan. Dengan itu, Dara sangat disukai oleh banyak cowok di sekolah terlebihnya hanya sebatas mengagumi. Berikut contoh penjelasan dalam novel Dua Garis Biru karya Lucia Priandarini yang menunjukkan hal tersebut.

"Setiap SMA punya "Dara”, gadis pintar, cantik, dan berbakat dari keluarga berada. Kembang sekolah yang seakan-akan tidak punya kekhawatiran apa pun selain memilih warna ikat rambut yang akan ia kenakan.

“... Sementara cowok-cowok jatuh hati tapi hanya berani mengagumi dari jauh.” (DGB, 2019: 11).

Dara yang menganakan pakaian terusan longgar rapi diacara lamarannya. Karena dengan perut yang semakin membesar pun Dara terlihat cantik dengan riasan wajahnya yang tergambar dalam kutipan di bawah ini. 
"Sementara itu di rumahnya, Dara mengenakan terusan longgar rapi. Satu dari sedikit pakaian di lemarinya yang masih dapat ia kenakan dengan perut membesar. Sepuluh menit lalu ia menyapukan riasan di wajah." (DGB, 2019: 126).

7. Kebutuhan Mengaktualisasikan Diri (Self Actialization)

Dara yang telah mampu dalam potensi dirinya, ada beberapa rencana yang Dara inginkan untuk mengukur potensi pada diri seperti mendata nama-nama perguruan tinggi yang Dara inginkan. Baik pada universitas yang tidak dikenal sekalipun. Dari kesekian pendataan perguruan tinggi yang Dara pilih semuanya di negara Korea. Selain Dara yang selalu mengidolakan artis Korea. Dara juga menginginkan tinggal di Korea dan mempunyai masa depan.

"Masih dipapan meja belajar, ada daftar nama-nama perguruan tinggi pilihan Dara. Nama-nama universitas yang bahkan tidak ia kenal. Semuanya sekolah Korea. Negara dan kehidupan di sana adalah impian dan masa depan Dara." (DGB, 2019: 14).

Kemampuan Dara yang dapat mengukur potensi pada dirinya. Dara betul-betul dan serius akan masa depannya di Korea. Bima dengan paham dan yakin tahu mau kemana Dara akan pergi untuk memilih masa depannya nanti setelah lulus sekolah. Selanjutnya, dapat diketahui bila terdapat tujuh kebutuhan aspek psikologis pada tokoh utama novel Dua Garis Biru meliputi kebutuhan fisiologis, kebutuhan rasa aman, kebutuhan sosial, kebutuhan untuk dihargai, kebutuhan estetis, dan kebutuhan mengaktualisasikan diri. Kebutuhan-kebutuhan tersebut teraktualisasi atau berhubungan pula dengan faktor lingkungan yang mempengaruhi situasi diri pada tiap tokoh.

\section{KESIMPULAN}

Aspek psikologis dalam tokoh utama novel Dua Garis Biru karya Lucia Priandarini menurut teori Abraham Maslow dapat disimpulkan bahwa kebutuhan fisiologis dalam novel Dua Garis Biru karya Lucia Priandarini dijelaskan bahwa Bima memenuhi kebutuhan fisik berupa seks, tidur, makan dan minum. Kebutuhan akan rasa aman dalam novel Dua Garis Biru karya Lucia Priandarini dijelaskan bahwa Bima yang selalu melindungi Dara dari keterpurukan. Kebutuhan sosial dalam novel Dua Garis Biru karya Lucia Priandarini dijelaskan bahwa Bima yang dulu dapat berinteraksi dan bersosial pada lingkup sekolah dan di rumah. Kebutuhan untuk dihargai dalam novel Dua Garis Biru karya Lucia Priandarini dijelaskan bahwa Bima dengan nilai akademik bisa dibilang rendah. Kebutuhan intelektual dalam novel Dua Garis Biru karya Lucia Priandarini dijelaskan bahwa Dara yang cerdas yang memiliki sejuta impian untuk melanjutkan kuliahnya diluar negeri. Kebutuhan estetis dalam novel Dua Garis Biru karya Lucia Priandarini dijelaskan bahwa Bima yang memakai kemeja panjang pada acara lamaran dengan Dara. Kebutuhan mengaktualisasikan diri dalam novel Dua Garis Biru karya Lucia Priandarini dijelaskan bahwa Dara yang berambisi melanjutkan kuliah di luar negeri.

\section{DAFTAR PUSTAKA}

Dewi dkk. 2019. Psikologi Tokoh Utama dalam Novel Pasung Jiwa Karya Okky Madasari: Kajian Psikologi Humanistik. Jurnal Imajeri, Vol. 1, No. 1, p. 69-76.

Ekawati Mona dan Nevi Yarni. 2019. Teori Belajar Berdasarkan Aliran Psikologi Humanistik dan Implikasi Pada Proses Belajar Pembelajaran. Jurnal Jurnal Review Pendidikan dan Pengajaran, Vol. 2, No. 2, p. 266-269. 
Endaswara. 2013. Metodelogi Penelitian Sastra Epistemologi, Model, Teori dan Aplikasi. Yogyakarta: CAPS (Center for Academic Publishing Service).

Halifah, Nur. 2013. Kajian Humanistik Psikologis Tokoh Protagonis dalam Novel Bumi Cinta Karya Habiburrahman El Shirazy. Jurnal Bahasa dan Sastra, Vol. 2, No. 1, p. 1-14.

Jarvis, Matt. 1993. Teori-Teori Psikologi: Pendekatan Modern untuk memahami perilaku, perasaan, dan Pikiran Manusia. Yogyakarta: Penerbit Kanisius.

Kasmi, Hendra. 2017. Kajian Humanisme dalam Novel-Novel Aceh. Jurnal Metamorfosa, Vol. 5, No. 1, p. 13-22.

Kurniawan dan Suharmono. 2017. Kepribadian Tokoh Utama dalam Skenario Film Door to Dor Kajian Humanistik Abraham Maslow. Jurnal Sapala, Vol. 3, No. 1.

Marwah dan Aam Abdussalam. Tinjauan Psikologis Humanistik dalam Pedagogik Spiritual. Jurnal Al-Musannif, Vol. 2, No. 1, p. 15-28.

Nurwatie, dkk. Perspektif Psikologi Humanistik Abraham Maslow dalam Meninjau Motif Pelaku Pembunuhan. Jurnal Ecopsy, Vol. 1, No. 4, p. 1-7.

Prahayu, Friesca Ardi Martha dkk. 2014. Kajian Psikologi Humanistik Novel Merpati Biru Karya Achmad Munif. Jurnal Publika Budaya, Vol 2, No. 2, p. 32-42.

Prakoso dan Latifatul Choir. 2009. Teori Humanisme. Malang: Universitas Negeri Malang.

Priandarini, Lucia. 2019. Dua Garis Biru. Jakarta: PT Gramedia Pustaka Utama.

Pohan, Nazli Hawalani. 2017. Faktor yang Berhubungan dengan Pernikahan Usia Dini terhadap Remaja Putri. Jurnal Endurance, Vol. 2, No. 3, p. 424-435.

Rachmahana, Ratna Syifa'a. 2008. Psikologi Humanistik dan Aplikasinya dalam Pendidikan. Jurnal El Tarbawi, Vol. 1, No. 1, p. 99-114.

Wiyatmi. 2011. Psikologi Sastra Teori dan Aplikasinya. Yogyakarta: Kanwa Publisher. 